\title{
Scanning Electron Microscopic Observations of the Vascular System of Rat Molar Pulps
}

\author{
By
}

\author{
Takako K. NAKAMURA \\ 2nd Department of Oral Anatomy, \\ Josai Dental University \\ Sakado 350-20, Japan
}

-Received for Publication, November 26, $1985-$

\begin{abstract}
Key words: Microcirculation, Vascular casts, Arteriovenous anastomoses, Rat molar pulps,
\end{abstract} Scanning electron microscopy.

\begin{abstract}
Summary. The present study was undertaken to investigate the entire microcirculation of rat molar pulps using Mercox and colloidal carbon injection methods in conjunction with SEM and LM.

In adult rats the casts of arteries often took a tortuous arrangement in all regions of molar pulps. The artery gave off two same-sized branches in the apical third of the radicular pulp, running parallel to each other. At the junction of the radicular and coronal pulp the arteries diverged into a radial-shaped pattern. The arteries entered coronal area where they divided into two groups, branching either towards the pulp horn or towards the coronal area.

Numerous capillaies were located just below the odontoblastic layer. In the pulp horn a rich capillary network was observed, while in the radicular pulp a diffuse network was seen.

Arteriovenous anastomoses occurred in the center of the coronal area where arterial and venous branches ran parallel to one another.

In immature rats the arteries took a nearly straight course in the radicular pulp.

In the present study tortuous arteries and arteriovenous anastomoses were observed in the pulpal vascular architecture. These tortuous arteries seem to be related to a stagnation of, or decrease in the blood supply. It is suggested that these particular vascular patterns regulate the blood flow throughout the pulp. Also the arteriovenous anastomoses may serve as an effective regulatory system of the pulpal blood circulation.
\end{abstract}

Microcirculation in the pulp is one of the interesting and important aspects in relation to physiological, anatomical, and pathological studies of oral structures. In order to study the blood vessels of dental pulp, various injection techniques employing dye solutions (Lepkowski, 1897; Boling, 1947), gelatin preparations (Russel and Kramer, 1956; Hada, 1957; Butcher and Taylor, 1957; Adams, 1959; Bernick, 1960, 1962; Kramer, 1960; Bennet et al, 1965; Kitamura and Nakajima, 1976), Latex (Kindolová and
Matěna, 1959, 1962) and radiopaque materals (Perint, 1949, Aoyagi, 1964) have been commonly used for histological visualization of the vessels. With these techniques, the distinction between arterial and venous divisions is made on the basis of the following criteria: 1) nature of the branching, 2) location, and 3) size. These studies have yielded much information on complex vascular patterns including relationships between dentin formation and capillary arrangement in the case of both continuously erupting teeth and ordi- 
nary teeth (Hada, 1957; Adams, 1959; Bernick, 1960, 1962; Kramer, 1960; Kindolová and Matěna, 1962; Klingsberg et al, 1959).

Currently, the Mercox injection technique is employed to examine the vascular arrangement of many tissues observed by scanning electron microscopy (Murakami, 1971; Fujita and Murakami, 1973; Lametschwandtner et al, 1976; Hodde et al, 1977; Kitamura et al, 1977; Iwaku and Ozawa, 1979; Anderson and Anderson, 1980; Draenert and Draenert, 1980; Takahashi et al, 1982; Nakamura et al, 1983). The study of the microcirculation by scanning electron microscopy has merits in its being able to show the dimensional constrictions of the vascular system, especially its branching and anastomosing arrangements. Furthermore, the most important benefit of this method is that arteries may be distinguished morphologically from veins. The surface of arteries shows relatively long and deep endothelial nuclear impression oriented in the direction of the long axis of the vessel. While the nuclear impressions of the venous wall show various shapes, spherical or ovoid, which are randomly oriented (Lametschwandtner et al, 1976; Hodde et al, 1977).

Since dental pulps are surrounded by dense hard tissue, it is difficult to visualize the vessels in them. Nevertheless some observations made by means of the resin injection method and scanning electron microscopy have been reported (Kitamura et al, 1977; Takahashi et al, 1982; Nakamura et al, 1983). Although rats are the most commonly used experimental animals for such studies, the vascular architecture of their molar pulps has been scarecely studied using the cast method.

The purpose of this study was to investigate the entire microvasculature of molar pulps of young adult, as well as of immature, rats by means of the Mercox injection technique in combination with scanning electron microscopy.

\section{Materials and Methods}

250 male Sprague-Dawley rats, some approximately $12-15$ weeks and others, 2-4 weeks old, were used in this study.

For light microscopy a solution containing $2 \%$ glutaraldehyde and $10 \%$ colloidal carbon in $0.1 \mathrm{M}$ cacodylate buffer $(\mathrm{pH} 7.4)$ was injected via the thoracic aorta into the animals under ether anesthesia. After fixation, mandibles were dissected and stored in fresh fixative at $4^{\circ} \mathrm{C}$ for one day and then decalcified in 5\% EDTA for 2 weeks. Following dehydration they were embedded by a routine technique in nitrocellulose or Araldite 502. The celloidin sections were stained with May-Grünwald; and Araldite sections, with toluidine blue.

For scanning electron microscopy the animals were anesthetized with ether, and then physiological saline was injected via the heart as primary perfusion. For secondary perfusion, $2 \%$ glutaraldehyde in $0.1 \mathrm{M}$ cacodylate buffer ( $\mathrm{pH} 7.4)$ was used, followed by Mercox (Dainippon Ink Co., Osaka, Japan) at physiological pressure. When the resin had hardened, the mandibles were removed. The specimens were macerat. ed in several changes of $2-10 \% \mathrm{NaOH}$ solution at $37^{\circ} \mathrm{C}$ until all organic tissues were completely digested (whole cast preparations). Other randomly selected samples of mandibles were excised, frozen in liquid nitrogen, and then fractured by a singleedge razor blade precooled in liquid nitrogen. The fractured samples were immersed in a solution of $15 \%$ prozyme (Kishi and Takahashi, 1976), $\mathrm{pH} 8.5$, at $37^{\circ} \mathrm{C}$, which was changer every day until the soft tissues were completely removed (fractured cast preparations). Vascular casts were washed overnight with tap water and then frozen in distilled water in a Petri dish. The frozen casts were then processed by a freeze-drying instrument (Vatillus U.S.A.). The dried casts were mounted, sputter coated (Ionsputter coater 1B-2, Eiko, Tokyo, Japan) 
with gold, and then viewed in a JSM-50A or JSM T-200 type scanning electron microscope at $25 \mathrm{kV}$.

\section{Results}

Rats have four teeth in each quadrant: three are molars and one is a very large incisor. The lower first molars have four roots which have a rhomboidal arrangement: the mesial and distal ones are large, but the other two are small and situated buccolingually. The second and third molars have three roots formed in a triangular arrangement: the distal root of the third is large and its mesiolingual root is in the same configuration as that in the three-rooted second molar.

Light microscopic observations were carried out on cross, mesio-distal, and bucco-lingual sections. Near the root apex in mature rats one or a few vessels entered into the radicular pulp and ran towards the coronal area. In the coronal area the vessels usually showed an abrupt increase in the number of branches which fanned out towards the surface. In the coronal cavity, which was covered with a thick dentin layer, the vessels were arranged in flat fashion near the floor of the chamber, probably due to the narrowness of the cavity. Within the pulp horn, vessels were abundant and their ramifications constant. The vessels often showed a tortuous course in all portions of the pulp chamber (Figs. 1-3).

A cross section of radicular pulp is shown in Figure 4. The vessels were located in the subodontoblastic layer and consisted of capillaries and small veins.

A low-power view by scanning electron microscopy of a cast preparation of a whole mount of an adult rat mandible is illustrated in Figure 5. The vessels of the molar pulps were enveloped by a high concentration of microvascular plexuses of the interdental septum, interalveolar septum, and gingiva.

\section{1) Arteries}

The inferior alveolar gave off several divisions at the mandibular canal or foraman. Root canal: In mature rats the main apical foramen and many minute foramina were present in each root. Figure 6 shows a lingual view of distal roots of a third molar in a whole cast preparation. Near the root apex the artery divided in to five to seven branches supplying the pulp and periodontal ligaments. The majority of them entered into the pulp, while a few were distributed to the periodontal ligaments. Before entering the pulp each artery took a slightly coiled course after branching. The fractured specimens also showed one or two arteries entering the apical foramen or accessory foramina (Figs. 7, 8). They were sometimes accompanied by veins. Shortly after entering the pulps, the arteries became bound together into an arterial bundle, which was located in the center of the radicular pulp. Figure 9 illustrated dichotomous arterial branches running parallel to each other, each of which showed about the same diameter in the apical third of the radicular pulp. However, the larger arteries branched continuously throughout the coronal third of the radicular pulp. The larger arteries often took a wavy course, while the smaller ones ran rather straight within the root canal (Fig. 10). The smaller arteries were located more peripherally in the radicular pulp, and they branched away towards the pulp-odontoblastic border area.

Near the radicular-cornonal border of the pulp, the arteries on the whole diverged into a radial-shaped pattern. Some of them divided dichotomously into branches of the same zize. While others proceeded in this area towards the center of the coronal area without branching. The main arterial path could be divided in to two divisions: one ascending towards the pulp horn (first type) 
and the other running horizontally to the center of the coronal area (second type) (Figs. 11-13). The path of each of these arteries was traced in the coronal area in detail.

Coronal area: For the first type of artery, a few of them entered the coronal area, giving off many secondary branches, including ascending and descending ones. Most of them entered into the pulp horn and become distributed within the coronal area. Both arteries and their branches had a distinctive and characteristic feature of taking a tortuous or coiled course after branching. The ascending and descending branches were distributed along the lateral wall; the former were located in the coronal area, while the latter went into the upper part of the radicular pulp (Fig. 14). Each branch broke up into small branches which anastomosed with similar vessels. Individual pulp horns were supplied by two or three arterioles which ramified into many fine vessels which then anastomosed with other neighboring vessels. Regional constrictions were frequently observed in the arterioles in this area.

For the second type of artery a few of them located in the center of the coronal area gave off several secondary branches. Each of these took an independent course (Fig. 15). One of them coalesced with other branches originating from other roots, forming arterial arches. Other branches ran towards the coronal roof and the lateral wall of the pulp chamber to supply the pulp of these areas.

Near the coronal-cuspal border the arteries showed a slightly coiled or tortuous arrangement (Fig. 16). The tortuous artries and arterioles showed deep impressions of endothelial cells in the cast specimens.

2) Capillary network

The arrangement of capillary networks differed according to location in the pulp chamber. Within the radicular pulp both capillaries and small veins were recognized. The number of capillaries was sparse compared with that of small veins. The capillaries were restricted to the pulp-odontoblastic border area and formed a diffuse network there (Fig. 17).

In the lateral wall of the coronal area a rich capillary network was located just below the odontoblastic layer. This capillary bed displayed an irregular arrangement (Fig. 18).

In the pulp horn the capillaries consisted of two layers of intricate and dense networks (Fig. 19).

The roof of the pulp chamber was sheathed by a layer of capillary network showing an irregular quadrilateral arrangement (Fig. 20).

\section{3) Veins}

The venous capillaries assembled in to small veins which then joined the vein reaching the main central vein. The main veins and arteries ran parallel to each other in the coronal area. These veins ran through the radicular pulp where they rejoined and became reduced in number as they approached the root apex. After leaving the apical foramen or foramina each vein joined with a large venous trunk in the periodontal ligament which finally drained in to the inferior alveolar vein.

\section{4) Arteriovenous anastomoses}

Arteriovenous anastomoses were observed mainly in the center of the coronal pulp where arterial and venous branches ran parallel to each other. They showed a slightly S-shaped course. Their lumina at the venous end were wider than those at the arterial end (Figs. 21, 22).

\section{5) Immature rats}

Immature rats had shorter roots. Histological observation showed that rich capillary networks existed along the entire pulpal surface. 
By scanning electron microscopic observations the molar vessels, including the small arteries, venous branches, and capillaries, were found to be completely filled with Mercox. Before entering the pulp the arteries assumed a slightly coiled arrangement after branching. In the radicular pulp they maintained a nearly straight course, while in the coronal area they took a curved path along the surface of the floor or roof of the coronal cavity. The general vascular arrangement in immature rats was similar to that found in the mature ones. The capillary networks surrounding the entire surface of the pulp cavity were visualized in the whole cast preparations (Figs. 23-28).

\section{Discussion}

In the present study, microvessels of rat molar pulps could be demonstrated quite well by the colloidal carbon and Mercox injection methods in conjunction with light and scanning electron microscopy. Each of these two methods has its merits and demerits: the light microscope allows a rapid screening, but at low resolution; while scanning electron microscopy allows microdissection, large depth of field, and wide range of magnification. Scanning electron microscopy also allows more detailed observations than light microscopy. Concerning the relationship between blood vessels and tissue elements, the combined techniques of injection and fracture are very useful to obtain information about this relationship. In the present study the vascular pathway of molar pulp was confirmed by these two different methods.

Hoffman and Schour (1940) studied the growth pattern of the primary and secondary dentin in molar teeth of rats varying in age from one to 500 days. They described that the cementum covered the root apex in increments up to 12 weeks, which agrees with my finding in this study. In the monkey molar pulp one or a few arteries accompanied with veins were found to pass through the foramen or foramina (Cutright and Bhaskar, 1969). This finding also agrees with the present study. Takahashi et al. (1979) described that each foramen of dog molar pulps was occupied by only one type of vessel. These differences may reflect characteristic properties of each species.

Another anatomical view was presented by Hoffman and Schour (1940); they described that the daily rate of apposition of primary dentin ranged from approximately $16 \mu \mathrm{m}$ in the weaning period to $1 \mu \mathrm{m}$ in animals 135 days old. Bernick (1962) reported some relationship between the rate of dentin apposition and capillary localization. Josephsen et al. (1974) noted from his histological observation the withdrawal of capillaries from the odontoblastic layer as the age of the rat increased. And Takahashi et al. (1979) noted that the capillary network in the dog pulp horn has loop-like structure. The present observation that the relative density of capillary networks in the coronal pulp is higher than that in the radicular pulp confirms previous findings (Hada, 1957; Kramer, 1960; Bernick, 1962; Josephsen et al., 1974), but special kind of capillaries were not observed in this study. Therefore, the heterogeneity of the capillary network within the pulp seems to be closely related to differences in metabolism.

A few other studies have been reported using the resin injection method and scanning electron microscopy to observe the vascular bed in dental pulp (Kitamura et al., 1976; Takahashi et al., 1979; Nakamura et al., 1983). In this study I observed constantly that arteries displayed a wavy or tortuous arrangement in all regions of the pulp in adult rats. They were marked clearly by the indented nuclear impression on the endothelial cell surface. 
Tortuous arteries were first reported by Trueta and Harrison (1953), who perfused with India ink the femoral head from adult human specimens obtained after death and observed its arterial pattern by light microscopy. Tortuous or coiled arteries were further reported by Anderson and Anderson (1978) in the circulation of dog coronary vessels and by Draenert and Draenert (1980) in the blood circulation of the rat tibial bone. Both workers employed resin injection methods followed by scanning electron microscopy.

Ordinary text books describe that arterioles, arteries, as well as precapillary arterioles, are coated discontinuously with smooth muscle cells. The contraction and relaxation of the muscular wall of arteries obviously influence the distribution of blood flow. Moreover, changes in blood composition such as the lack of oxygen or accumulation of carbon dioxide tend to cause relaxation of smooth muscle, resulting in vasodilation. As a result of these effects the rate of blood flow may become two to six times greater than it was before (Bloom and Fawcett, 1975). Anderson and Anderson (1978) suggested that contraction of the single discontinuous layer of smooth muscle of the vessel might produce a spring-like action of the precapillary arteriole in the dog heart.

In rat dental pulp, Kindolová and Metěna (1962) observed following latex injection that the arteries had a straight course, while the veins took a wavy one. Hada (1957) suggested that arteries showing a tortuous pattern in the radicular pulp of rats are the result of aging, in which the cavity tends to become narrower. The results of the present study suggest that blood flow is effectively reduced or stored in this area. Thus, these tortuous arteries might serve to regulate blood flow through the dental pulp.
In anatomical studies of arteriovenous anastomoses, skin (Prichard and Daniel, 1953; Dawes and Prichard, 1953 Sherman, 1963; Hales et al, 1978; Svanes, 1980 Morris, 1984) has been the most commonly used material since the anastomoses there are known to have an important role in thermoregulation. Furthermore, experimental studies have shown that arteriovenous anastomoses are affected by changes in blood composition, such as result from hypoxia (Sherman, 1963), or by changes in $\mathrm{pH}$ in the case of the circulation in the stomach (Walder, 1952).

From transmission electron microscopic observations, anastomoses in the human nose (Cauna, 1970) and rat tail (Kondo, 1972) show a close proximity to vasomotor nerve endings, suggesting that anastomoses are controlled by such nerve endings.

In the dental pulp the presence of arteriovenous anastomoses was first demonstrated by Kramer (1960) who attempted the injection of dye directly into the apical foramen of extracted human teeth. Then later, Provenza (1964) also observed anastomoses in histological sections of extracted human teeth. Kramer suggested that arteriovenous anastomoses may play a role in the local regulation of the dental circulation. However, the exact functional significance of the arteriovenous anastomoses in the dental pulp is not clear.

The present study demonstrates that the entire arrangement of molar vessels of the mandible are complicated, indicating that the blood flow in the pulp may also be complex. The finding of arteriovenous anastomoses in the present study supports Kramer's and Provenza's descriptions. For the regulation of blood flow the arterial sphincters and arteriovenous anastomoses play an effective role. The precapillary sphincters regulate the flow to their capillary networks. In the arteriovenous anastomoses 
the blood can be transported effectively through short thoroughfares, and such a capillary bypassing system helps to regulate the flow of the overall circulation in the tissue. The results of the present study suggest that arteriovenous anastomoses may serve as an effective regulator of the circulation in the molar pulp.

\section{Acknowledgement}

The author is much obliged to Prof. Hiroshi Hanai for his keen interest in this subject and for improvement of this manuscript.

\section{References}

1) Adams, D.: Periperal capillaries in the rodent incisor pulp. J. Dent. Res., 38: 969-978, 1959.

2) Anderson, B.G. and Anderson, W.D. : Microvasculature of the canine heart demonstrated by scanning electron microscopy. Am. J. Anat, 158: 217-227, 1980.

3) Aoyagi, F. Microangiogram of human dental pulp vessels. Bull. Tokyo Dent. Coll., 5: 59-69, 1964.

4) Bennett, C.G., Kelln, E.E. and Biddington, W.R.: Age changes of the vascular pattern of the human dental pulp. Arch Oral Biol., 10: 995-998, 1965.

5) Bernick, S.: Vascular supply to the developing teeth of rats. Anat. Rec., 137: 141-151, 1960.

6) Bernick, S. Age changes in the blood supply to molar teeth of rats. Anat. Rec., 144: 265274, 1962.

7) Bloom, W. and Fawcett, D.W.: Blood and Lymph vascular systems. In Histology, $A$ Textbook Tenth Ed, Saunders, W.B. Co., Philadelphia, London, Tronto, pp. 386-426, 1975.

8) Boling, L.R.: Blood vessels of dental pulp. Anat. Rec., 82: 25-37, 1947.

9) Butcher, E.D. and Taylor, A.C.: The vascularity of the incisor pulp of the monkey and its alternation by tooth retraction. J. Dent. Res., 31 : 239-247, 1957.

10) Cauna, N.: The fine structure of the arterio- venous anastomosis and its nerve supply in the human nasal respiratory mucosa. Anat. Rec., 168: 9-22, 1970.

11) Cutright, D.E. and Bhaskar, S.N.: Pulpal vasculature as demonstrated by a new method. Oral Surg. Oral Path., 27: 678-683, 1969.

12) Dawes, J.D.K. and Prichard, M.M.L.: Studies of the vascular arrangements of the nose. J. Anat., 87 : 311-322, 1953.

13) Draenert, K. and Draenert, Y.: The vascular system of bone marrow. SEM/1980, IV Research Institute, Chicago, II 60666, 113112.

14) Fujita, T. and Murakami, T.: Microcirculation of monkey pancreas with special reference to the insuloacinar portal system. A scanning electron microscope study of vascular casts. Arch. Histol. Jpn., 35: 255-263, 1973.

15) Hada, J.: On the distribution of the minute blood vessels of the teeth and jaw of the Rattus norvegicus albus. J. Hiroshima Med. Assoc., 10: 699-707, 1957. (Japanese with English summary)

16) Hales, J.R.S., Fawcett, A.A., Bennett, J.W. and Needham, A.D.: Thermal control of blood flow through capillaries and arteriovenous anastomoses in skin of sheep. Pfüger Arch., 387: 55-63, 1978.

17) Hodde, K.C., Miodónski, A., Bakker, C. and Veltman, W.A.M.: Scanning electron microcorrosion casts with special attention on arteriovenous differences and application to the rat's cochlea. SEM/1977, II Research Institute, Chicago, Il 60616, 477-484.

18) Hoffman, M.M. and Schour, I.: Quantitative studies in the development of the rat molar. I. The growth pattern of the primary and secondary dentin (From birth to 500 days of age). Anat. Rec., 78: 233-249, 1940.

19) Hoffman, M.M. and Schour. I. : Quantitative studies in the development of the rat molar. II. Alveolar bone, cementum and eruption (From birth to 500 days). Am. J. Orthodont., 26: 854-874, 1940.

20) Iwaku, F. and Ozawa, H.: Blood supply of the rat periodontal space during amelogenesis as studied by injection replica SEM method. Arch. Histol. Jpn., 42: 81-88, 1979.

21) Josephsen, K., Fejerskov, O. and Theilade, J.: Age changes in jux taodontoblastic capillaries of rat molars. Scand. J. Dent. Res., 82: 574$578,1974$.

22) Kindolová, M. and Maténa, V.: Blood circulation in the rodent teeth of the rat. Acta 
Anat., 37: 177-189, 1959.

23) Kindolová, M. and Matena, V.: Blood vessels of the rat molar. J. Dent. Res., 41: 650-660, 1962.

24) Kishi, Y. and Takahashi, K.: A scanning electron microscopic study of the vascular architecture of the periodontal membrane. Jpn. Oral Biol., 19: 192-207, 1977. (Japanese with English summary)

25) Kitamura, T., Kunii, S., Nakajima, T. and Hanai, H.: Preliminary report of the construction of peripheral capillaries in rat incisor pulp. Bull. Josai Dent. Univ., 6: 25-27, 1977. (Japanese with English summary)

26) Kitamura, T. and Nakajima, T.: Morphological observation of blood vessels injected with colloidal carbon in rat incisors. Bull. Josai Dent. Univ., 3: 29-33, 1976.

(Japanese with English summary).

27) Klingsberg, J., Cancellaro, L. and Butcher, E. O.: A capillary network in the odontoblastic layer of developing teeth. J. Dent. Res., 38: 419, 1959.

28) Kondo, H: An electron microscopic study on the caudal glomerulus of the rat. J. Anat., 113: 341-358, 1972.

29) Kramer, I.R.H.: The vascular architecture of the human dental pulp. Arch. Oral Biol., 2: $177-189,1960$.

30) Lametschwandtner, A., Simonsberger, P. and Adam, H.: Scanning electron microscopical studies of corrosion casts. The vascularization of the paraventricular organ (organon vasculosum hypothalami) of the toad Bufo bufo (L.). Mikroskopie 32,S: 195-203, 1976.

31) Lepkowski, W.: Über die Gefässverteilung in den Zähnen von Säugetieren. Anat. Heft, 8: $561-588,1897$.

32) Morris, J.L. and Bevan, R.D.: Development of the vascular bed in the rabbit ear: Scanning electron microscopy of vascular corrosion casts. Am. J. Anat., 171: 75-89, 1984.

33) Murakami, T. : Application of the SEM to the study of the blood vessels. Arch. Histol. Jpn., 32: 445-454, 1971.

34) Nakamura, T.K., Hanai, H. and Nakamura, M.T.: Transmission and scanning electron microscopic studies of blood vessels of rabbit molar pulp. Jpn. J. Oral Biol., 25: 263274, 1983. (Japanese with English summary)

35) Perint, E.J.: Detailed roentgenologic ex amination of the blood supply in the jaws and teeth by applying radiopaque solutions. Oral Surg., 2: 2-18, 1949.

36) Prichard, M.M.L. and Daniel, P.M.: Arteriovenous anastomoses in the tongue of the dog. J. Anat., 87: 66-74, 1953.

37) Provenza, D.V.: Dental pulp. In Oral Histology Inheritance and Development. J.B. Lippincott Co., Philadelphia, pp. 253-288, 1964.

38) Russel, L.H. and Kramer, I.R.H. : Observations on the vascular architecture of the dental pulp. J.Dent. Res., 35: 957, 1956.

39) Sherman, J.L.Jr.: Normal arteriovenous anastomoses. Medicine (Baltimore), 42: 247$267,1963$.

40) Svanes, K.: Effect of temperature on blood flow. In Microcirculation. Vol. III. Ed, Kaley, G.; Altura, B.M., Univ. Park Press, Baltimore, pp. 21-42, 1980.

41) Takahashi, K., Kishi, Y. and Kim, S.: A scanning electron microscope study of blood vessels of dog pulp using corrosion resin casts. J. Endod., 8: 131-135, 1982.

42) Trueta, J. and Harrison, M.H.M.: The normal vascular anatomy of the femoral head in adult man. J. Bone Jt. Surg., 35-A: 442$461,1953$.

43) Walder, D.N. : Arteriovenous anastomoses of the human stomach. Clin. Sci., 11: 59-71, 1952. 


\section{PLATES}




\section{Explanation of Figures}

\section{Plate I}

Fig. 1. Light micrograph of lower first molar of a mature rat. Pulp after perfusion with colloidal carbon, showing multiplicity of vessels entering and leaving the apical foramina. Bucco-lingual celloidin section stained with May-Grünwald. $\times 30$.

Fig. 2. Lower first molar as seen in medio-distal section. Blood vessels taking a tortuous course from radicular to coronal area. Celloidin section stained with May-Grünwald. x30.

Fig. 3. Higher magnification of vessel pattern in the coronal area. Tortuous parent and daughter vessels are seen. $\times 100$.

Fig. 4. Araldite semi-thin cross section of radicular pulp of mature rat. Capillary localization is restricted to the pulp-odontoblastic border area. Toluidine blue stain. $\times 40$. 

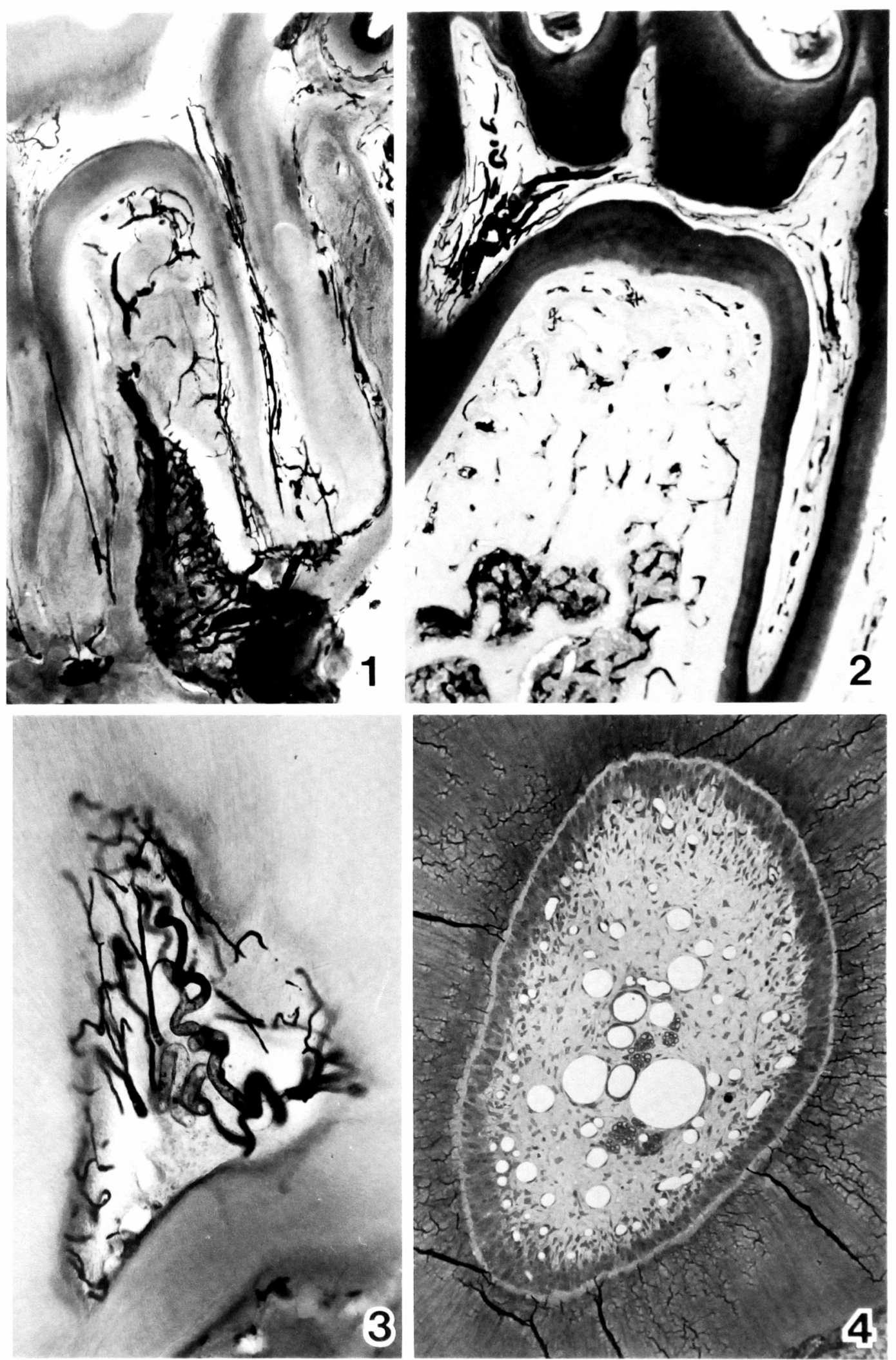


\section{Plate II}

Fig. 5. Low-power scanning electron micrograph of whole vascular cast from mandible preparation of mature rat. Molar pulps $\left(\mathrm{M}_{1}-\mathrm{M}_{3}\right)$ covered with dense vascular plexuses of interdental septum (DS), interalveolar septum (AS), and gingiva (G). $M_{1}$ : First molar, $M_{2}$ : Second molar, $M_{3}$ : Third molar. $x 18$. 


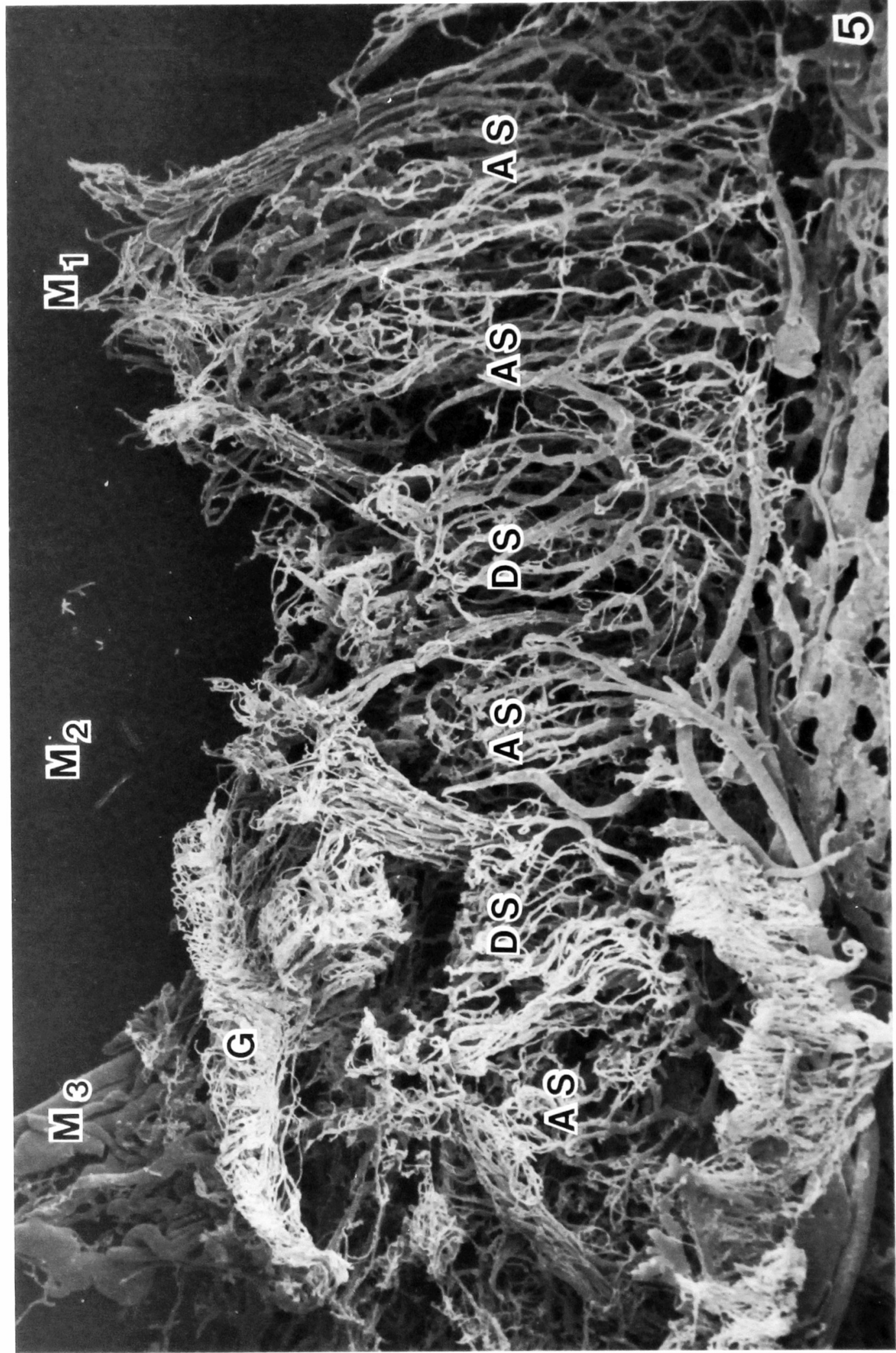




\section{Plate III}

Fig. 6. Whole cast preparation of dental root of third molar. Arteries are seen running through the center of the radicular pulp; they display a tortuous arrangement after branching. 5-7 major arteries (A) are evident within the pulp, and a few supply the periodontal ligament (PDL) near the root apex. (*) indicates vessels originating from the periodontal ligament. $\times 85$.

Fig. 7. Fractured cast of medio-distal preparation. Showing a tortuous artery before entering root canal. D: Dentin, AB: Alveolar bone, V: Vein, A: Artery, PDL: Periodontal ligament. $\times 180$.

Fig. 8. Large and small foramina are seen in apex of root. $\times 30$. 


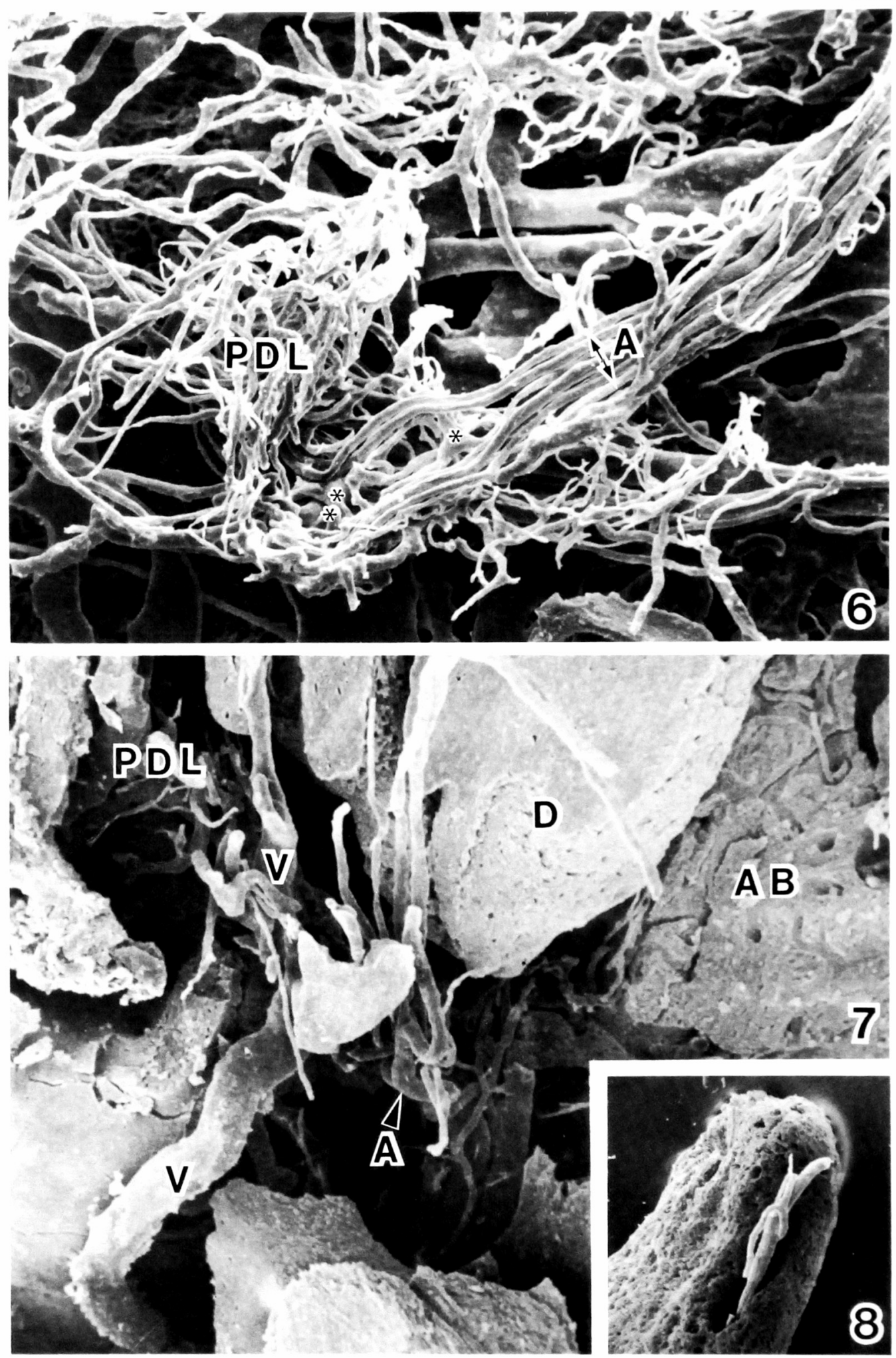




\section{Plate IV}

Fig. 9. Fractured cast preparation of third molar pulp. Showing proportional branching of artery at the apical third of the radicular pulp (arrowhead). V: Vein, D: Dentin. $\times 120$.

Fig. 10. Whole cast preparation of first molar pulp. Showing arteries (A) running in a wavy course in the radicular pulp. $\times 180$. 


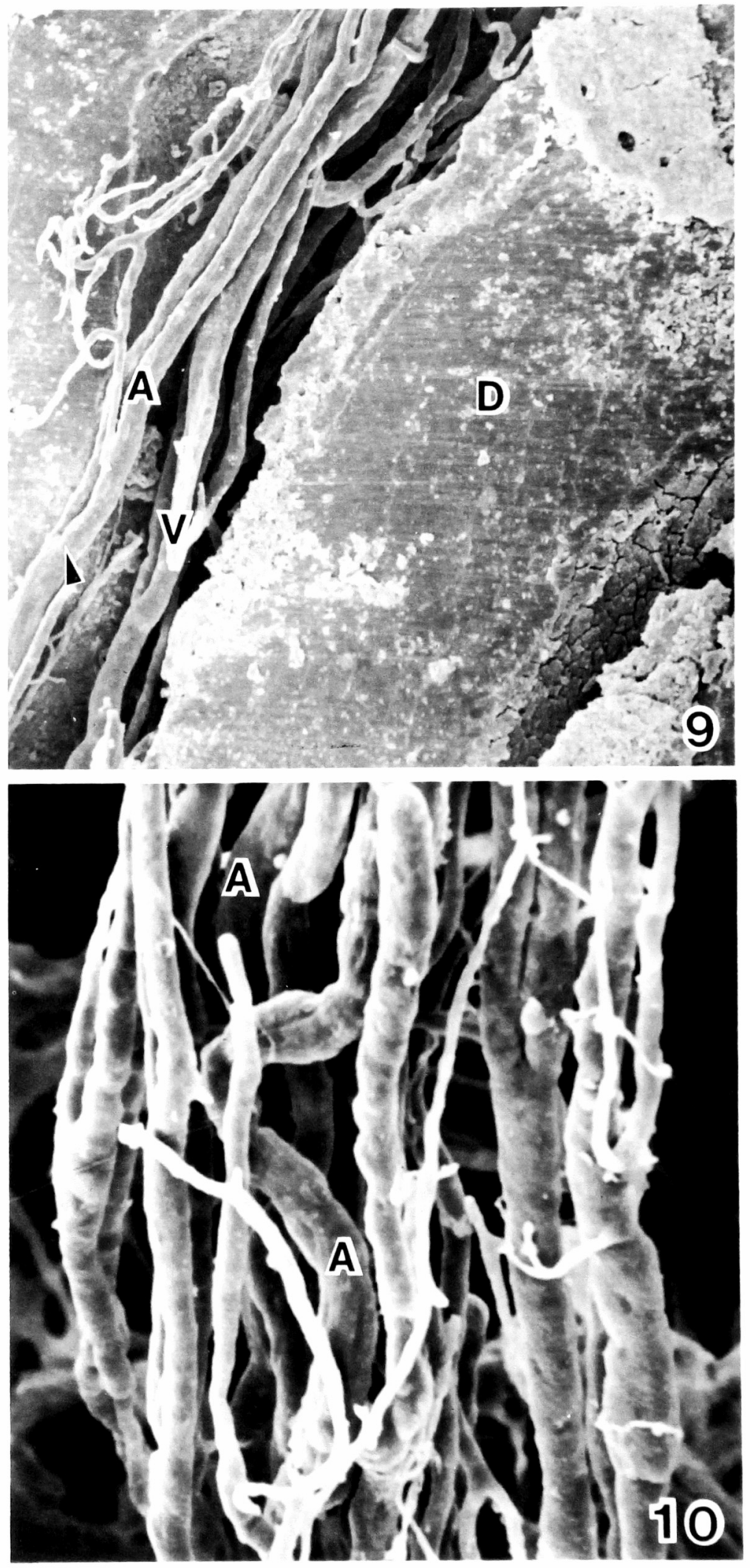




\section{Plate V}

Figs. 11-13 Whole cast preparations of second molar pulp.

Fig. 11. Main vessels covered with capillaries. $x 60$.

Fig. 12. Dissected capillaries showing features of arteries (A) at the radicular-coronal border.

Arterial branches running independently, which are classified into two groups: one is the pulp horn $\left({ }^{\circ}\right)$; and the other, the coronal pulp $(*) . \times 90$.

Fig. 13. Higher magnification of a portion of the radicular-coronal border showing tortuous arteries (A). AS: Interalveolar septum. $\times 220$. 

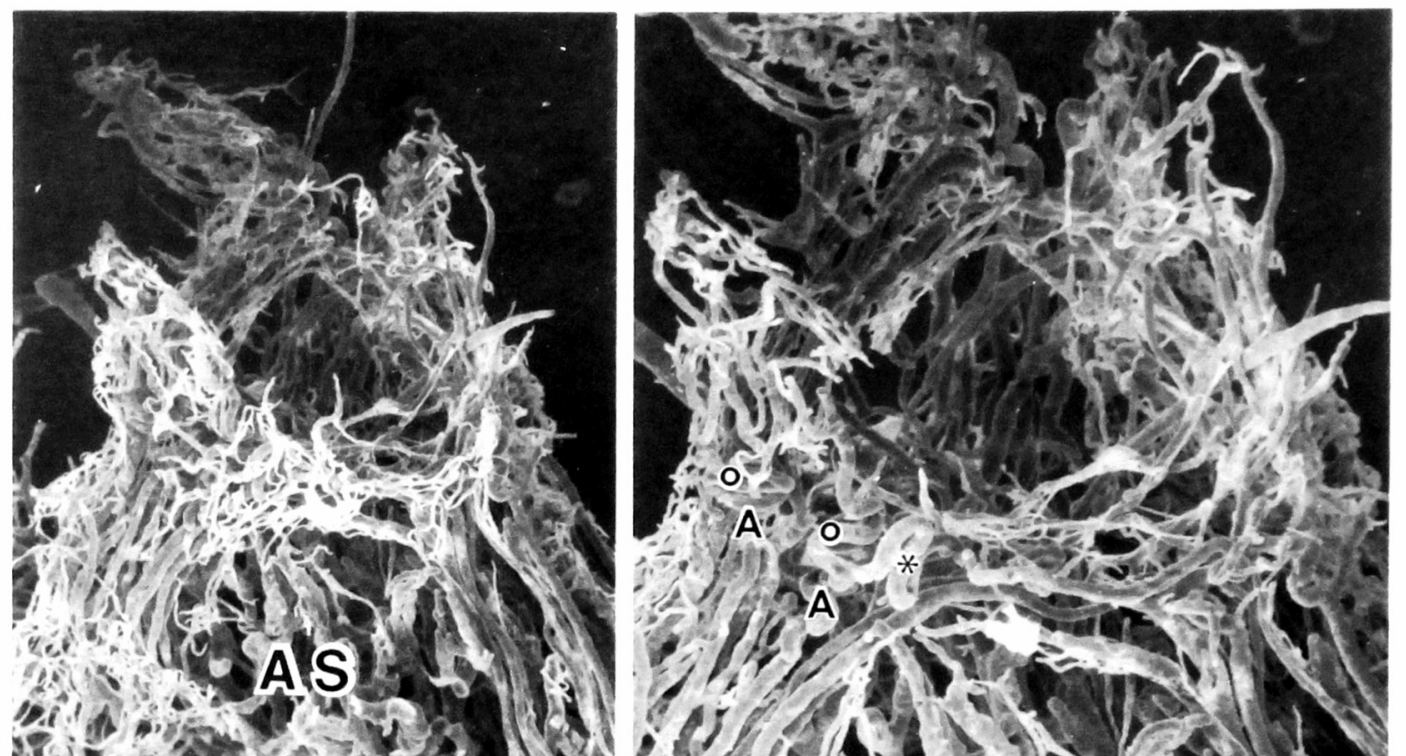

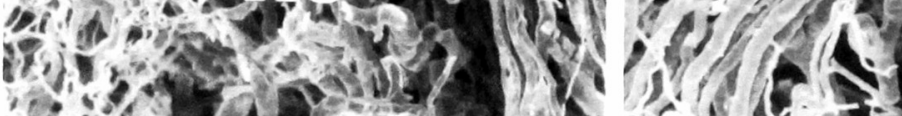

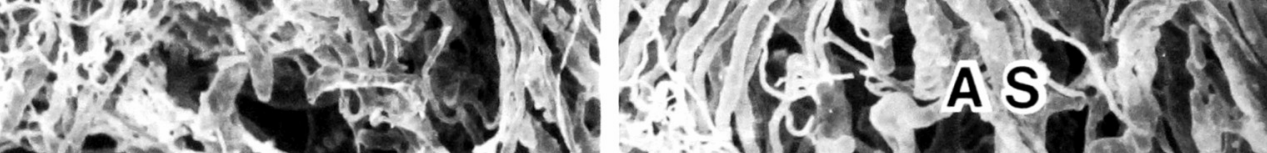

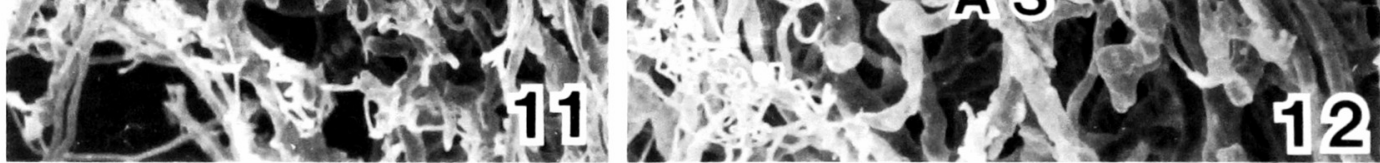

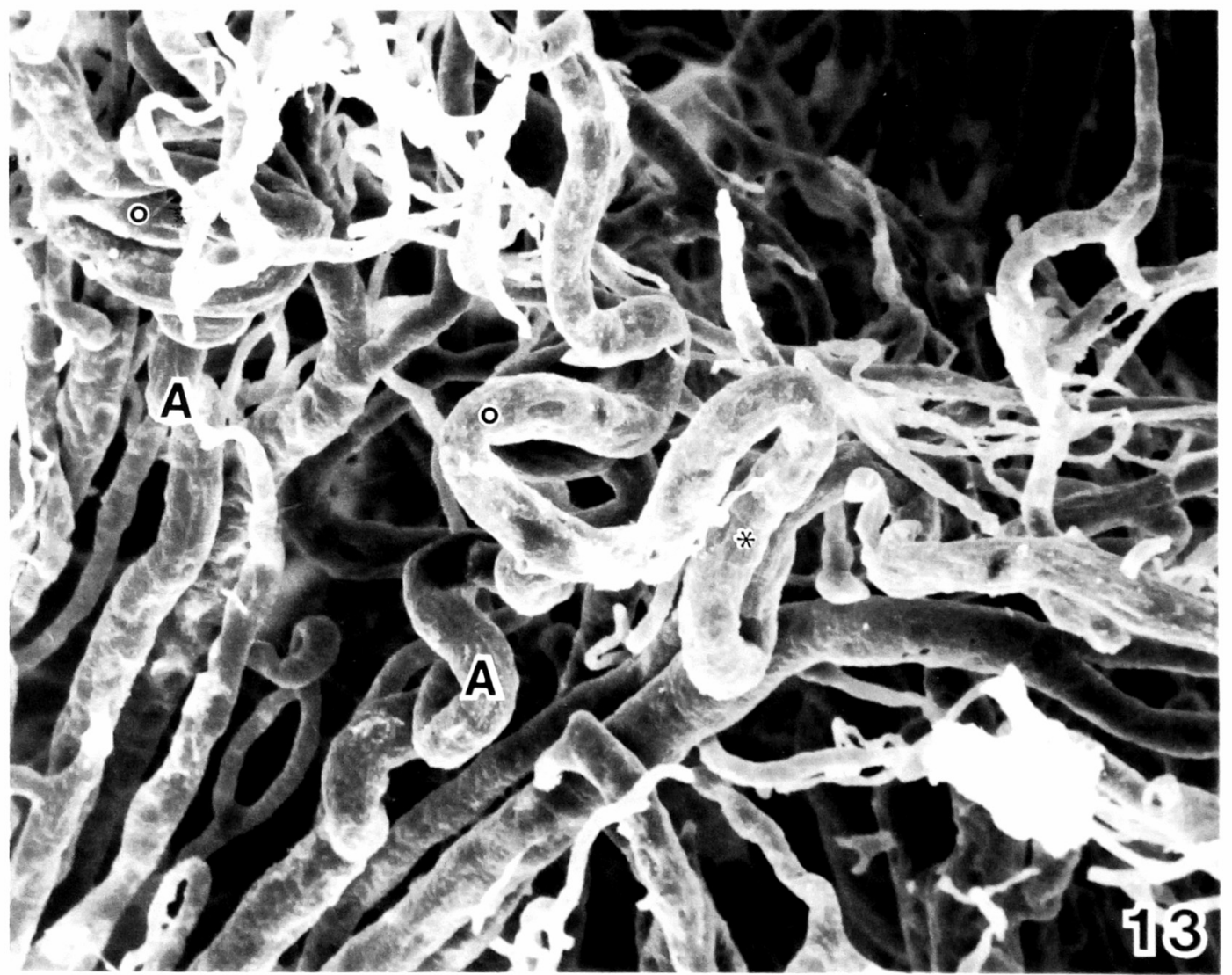




\section{Plate VI}

Fig. 14. Fractured cast preparation of second molar. Showing tortuous arteries (A) near the radicularcoronal border of the pulp chamber. D: Dentin. $\times 180$.

Fig. 15. Fractured cast preparation of first molar. Showing sharply bending artery in the center of coronal pulp. Arterial branches independently supplying coronal area.

R: Roof of pulp chamber, F: Floor of pulp chamber, B: Vascular bundle of radicular pulp. $\times 220$.

Fig. 16. Fractured cast preparation of third molar. Showing a special kind of artery (A) at the coronalcuspal border area. V: Vein. $\times 350$. 
Plate VI
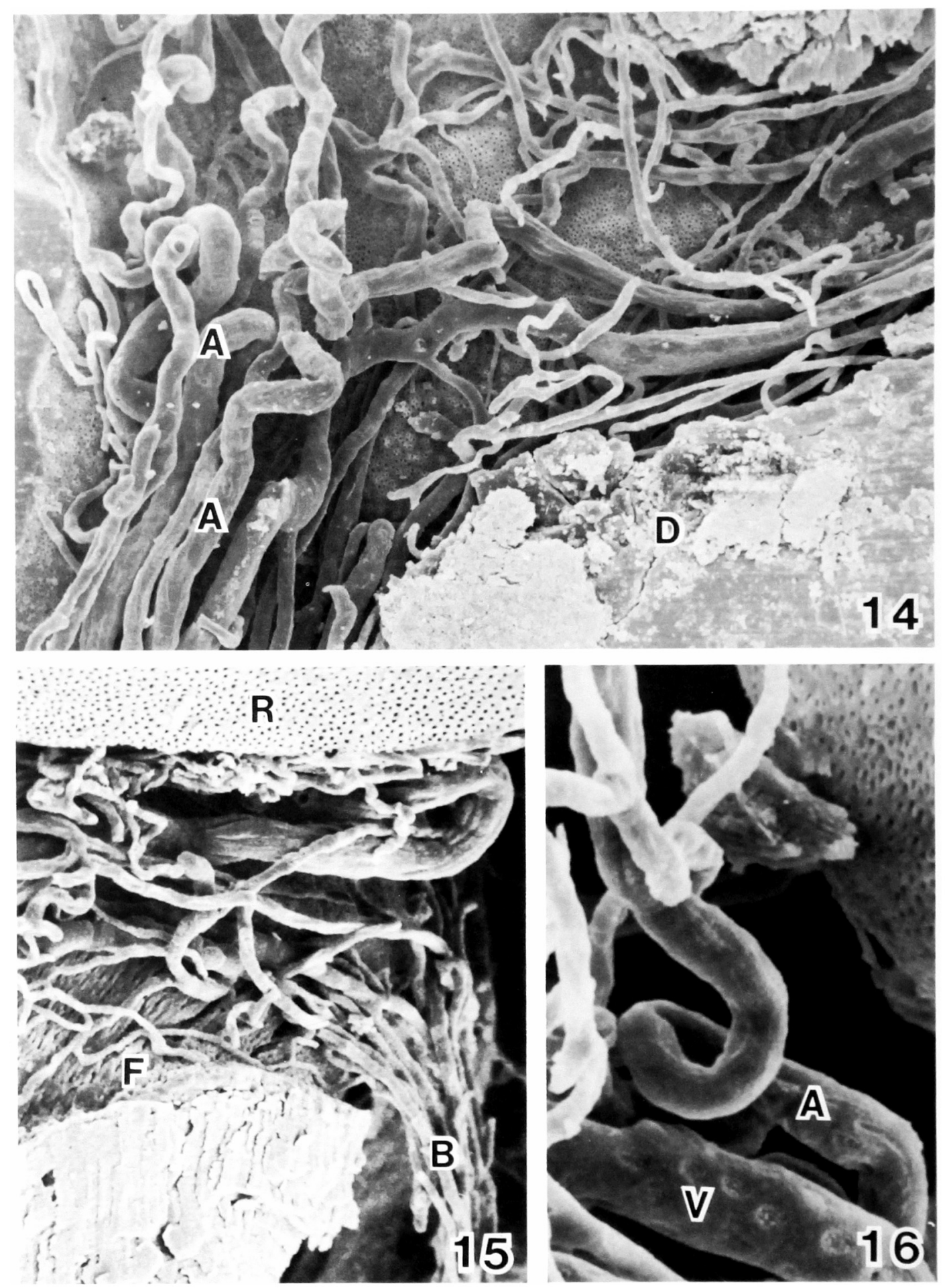


\section{Plate VII}

Figs. 17, 18. Capillary network of rat molar pulp.

Fig. 17. Radicular pulp. Rough capillary network in radicular pulp of mature rat. $\times 180$.

Fig. 18. Lateral wall of coronal pulp. Capillaries arranged in an irregular square-shaped net work. $\times 180$. 
Plate VII

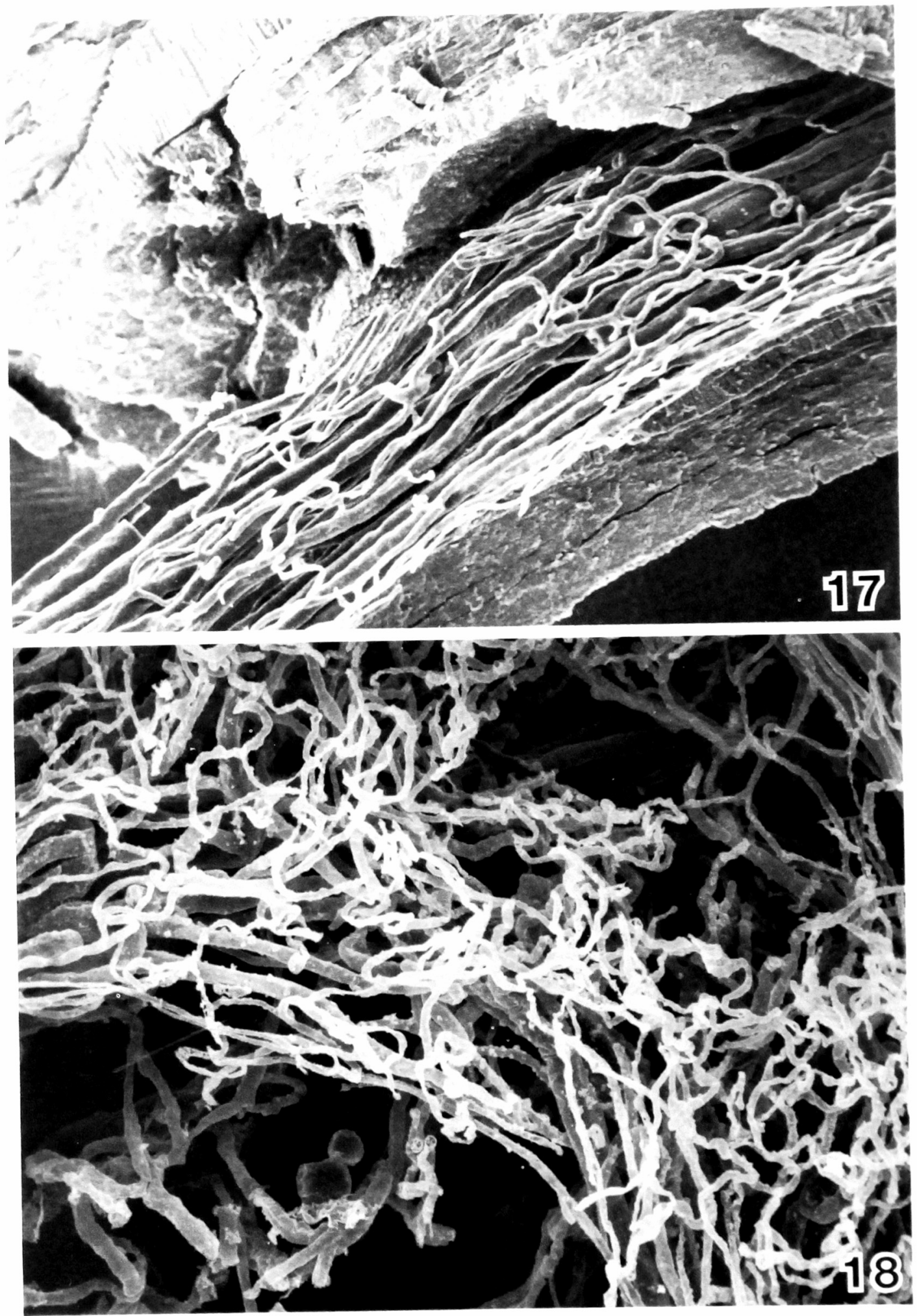




\section{Plate VIII}

Figs. 19, 20 Capillary network of rat molar pulp.

Fig. 19. Pulp horn. A rich network of capillaries arranged in an intricate and freely anastomosing fashion. $\times 400$.

Fig. 20. Roof of pulp chamber (R). Capillaries arranged in a layer showing an irregular quadrilateral-shaped network. $\times 120$. 

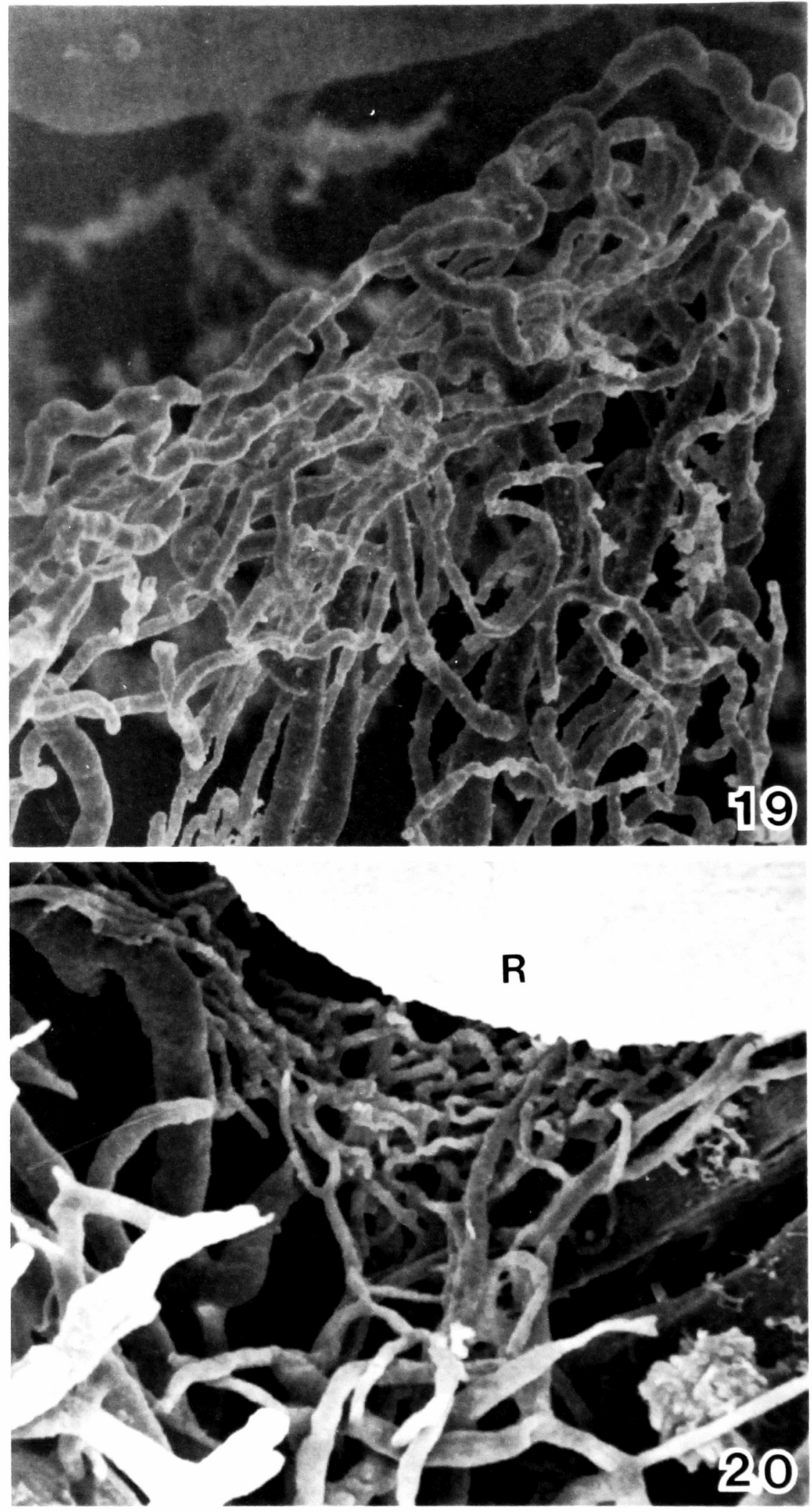


\section{Plate IX}

Figs. 21, 22. Arteriovenous anastomoses (arrowheads) in the coronal area. These occur where arterial and venous branches run parallel to each other. A: Artery, V: Vein. $\times 400$. 


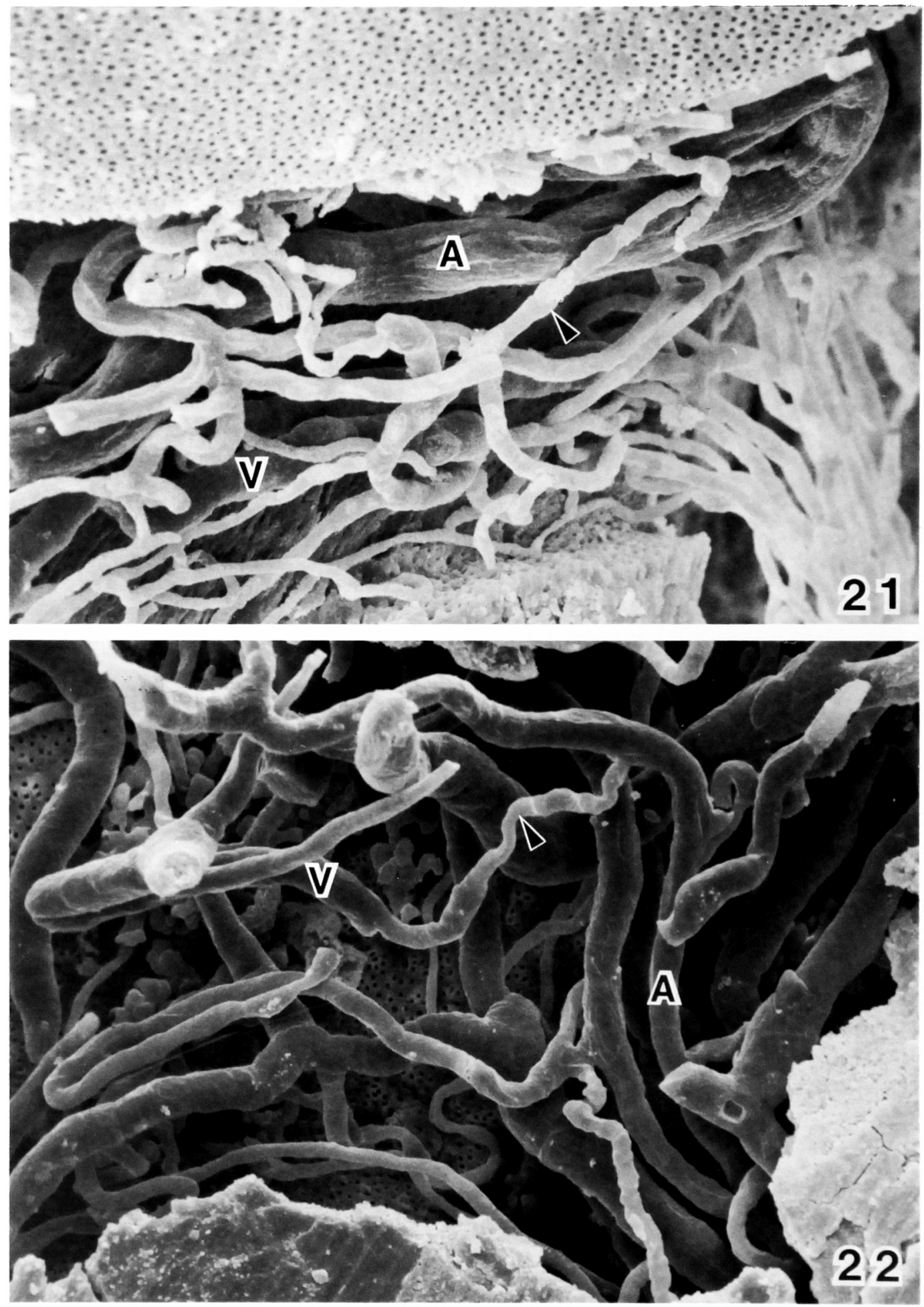




\section{Plate X}

Fig. 23. Celloidin section of immature rat molar (2-4 weeks old). The blood vessels are injected with colloidal carbon. Vessels are running a straight course in the radicular pulp. The surface of the pulp chamber is richly covered with capillaries. May-Grünwald stain. $\times 30$.

Fig. 24. Lower first molar of immature rat. Low magnification of scanning electron microscopy of root apex. Roots are short. $\times 70$.

Fig. 25. Low magnification of whole cast preparation of first molar pulp of immature rat. DR: Distal root, MR: Medial root, IR: Intermediate root, AS: Interalveolar septum. A: Artery. $\times 60$. 

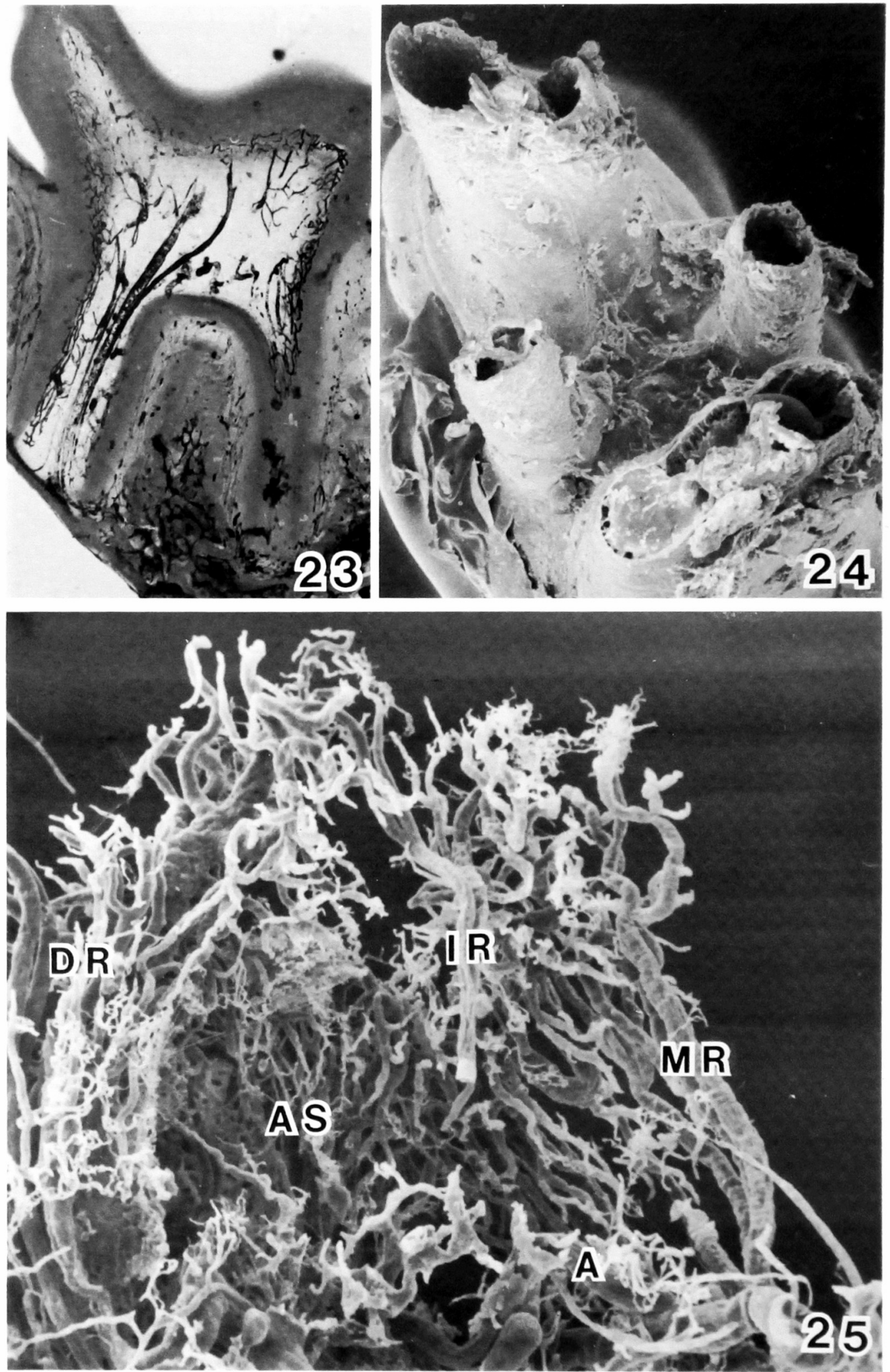


\section{Plate XI}

Figs. 26, 27 Whole cast preparation of first molar pulp.

Note rich capillary covering of the surface of main vessels. Fig. 26. MR: Medial root. DR: Distal root, IR: Intermediate root. $\times 60$. Fig. 27. Higher magnification of a portion of radicular pulp of Fig. 26 . Arteries (A) taking a straight course through the root canal. $\times 120$. 


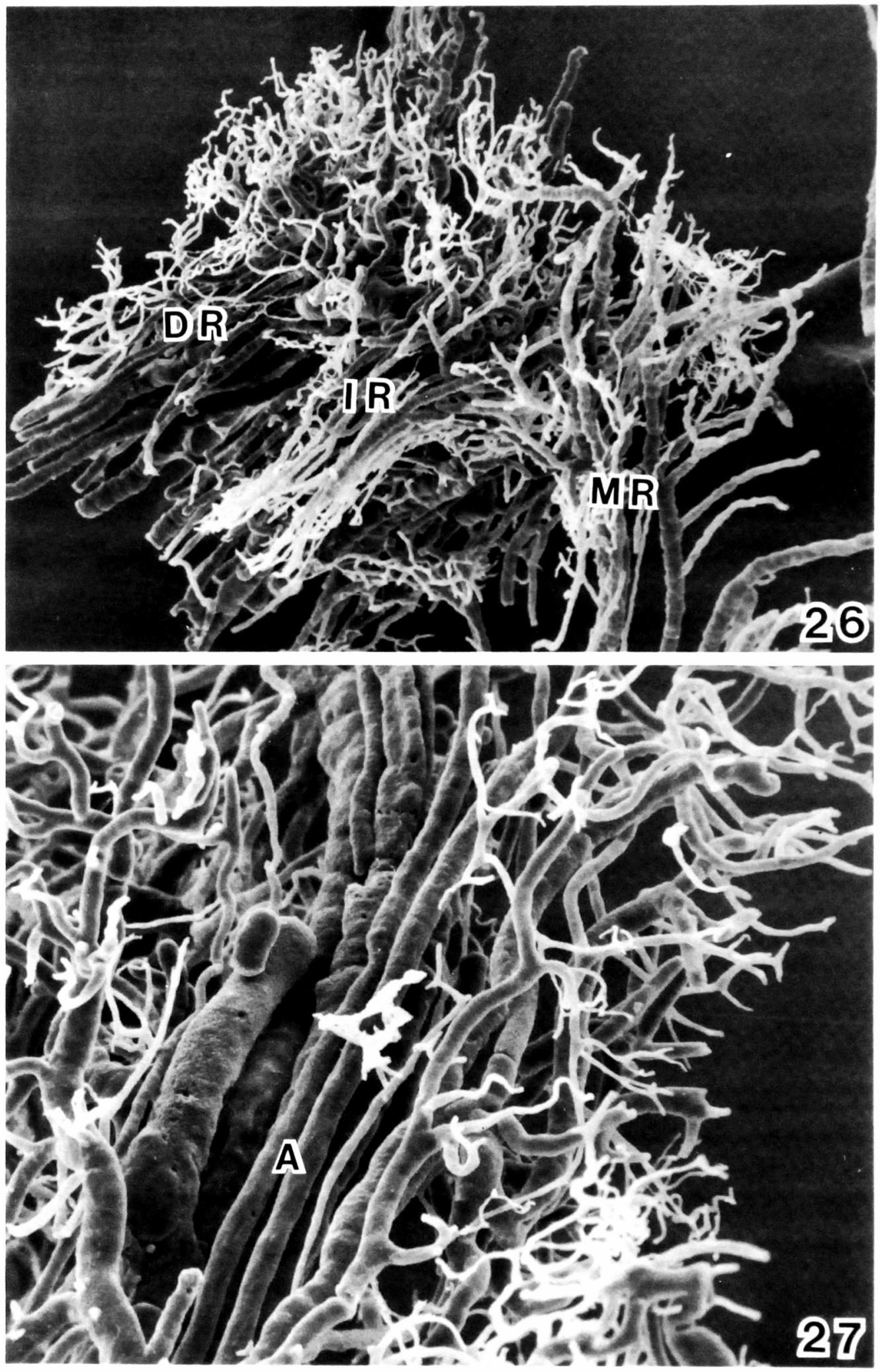




\section{Plate XII}

Fig. 28. Whole cast preparation of first molar pulp.

Showing a portion of the coronal area. Arterial (A) arrangements taking on a curved shape corresponding to the features of the pulpal wall. $\times 180$. 


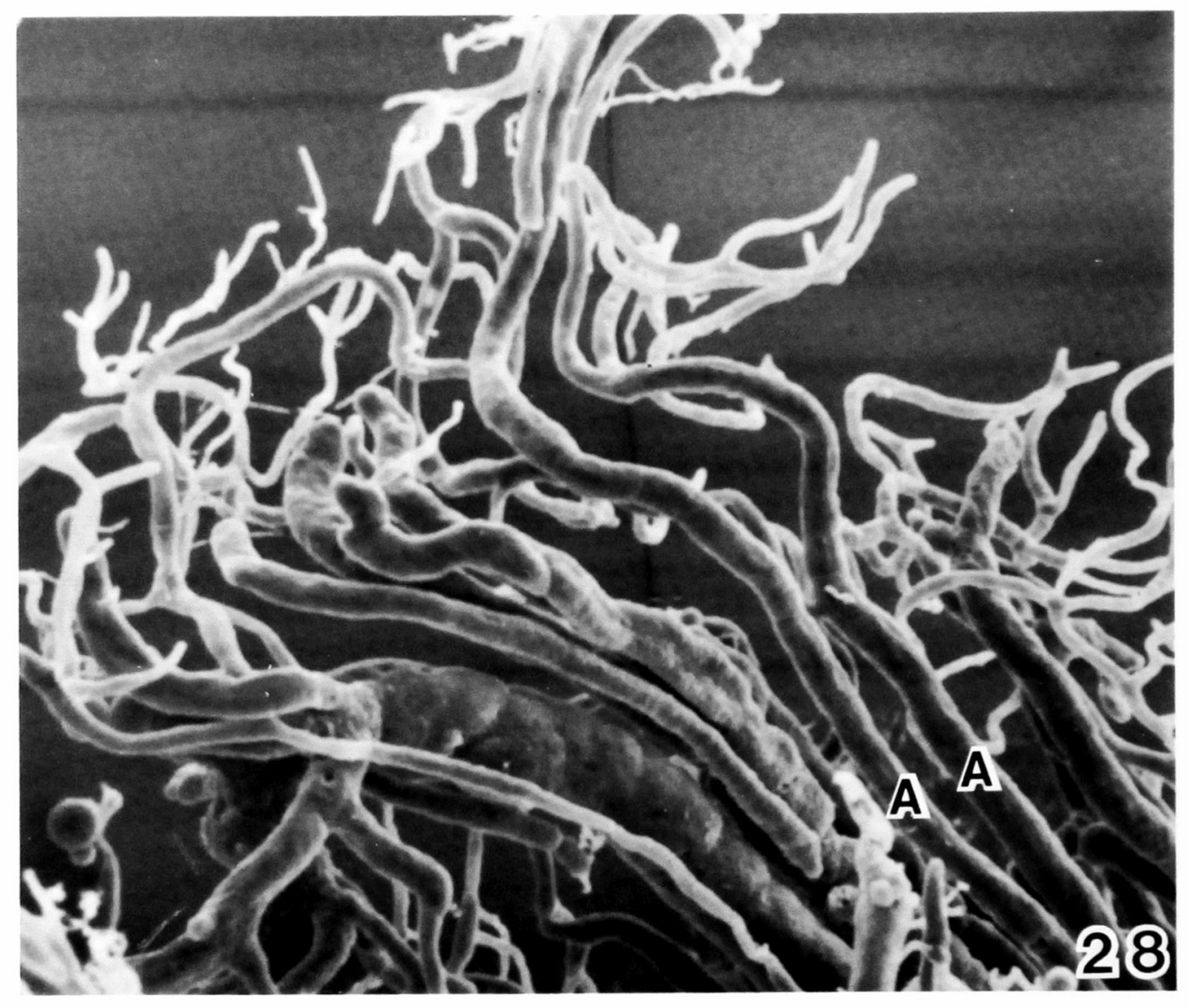

